\title{
Prognostic significance of HER3 in patients with malignant solid tumors
}

\author{
Qin Li ${ }^{1}$, RuiXue Zhang ${ }^{2}$, Han Yan ${ }^{1}$, PengFei Zhao ${ }^{1}$, Li Wu ${ }^{3}$, Hui Wang ${ }^{3}$, Teng Li $^{1}$ and \\ Bangwei Cao ${ }^{1,4,5}$ \\ ${ }^{1}$ Department of Oncology, Beijing Friendship Hospital, Capital Medical University, Beijing 100050, China \\ ${ }^{2}$ Department of Internal Medicine, The First Hospital, Tsinghua University, Beijing 100016, China \\ ${ }^{3}$ Department of Health Statistics, School of Public Health, Shanxi Medical University, Taiyuan 030001, China \\ ${ }^{4}$ Beijing Key Laboratory for Precancerous Lesion of Digestive Diseases, Beijing Friendship Hospital, Capital Medical University, \\ Beijing 100050, China \\ ${ }^{5}$ Beijing Digestive Diseases Center, Beijing Friendship Hospital, Capital Medical University, Beijing 100050, China \\ Correspondence to: Bangwei Cao, email: oncologychina@163.com \\ Keywords: HER3, malignant tumors, prognosis, molecular markers, immunohistochemistry \\ Received: August 10, $2016 \quad$ Accepted: March 21, $2017 \quad$ Published: May 18, 2017 \\ Copyright: Li et al. This is an open-access article distributed under the terms of the Creative Commons Attribution License 3.0 (CC BY 3.0), \\ which permits unrestricted use, distribution, and reproduction in any medium, provided the original author and source are credited.
}

\section{ABSTRACT}

\begin{abstract}
Human epidermal growth factor receptor 3 (HER3) is closely involved in tumor progression and is an important target of therapy. To evaluate the prognostic significance of HER3 in malignant solid tumors, we searched the PUBMED, EMBASE and CNKI databases for relevant studies written in English or Chinese up to December 2015. Fifteen studies comprising 2964 patients were identified. The $\mathrm{HER3}^{+}$rate ranged from 9.0-75.1 $\%$ in malignant solid tumors: $30.3-75.1 \%$ in breast cancers, 51.1-74.5 \% in colorectal cancers, 13.7-59.0 \% in gastric cancers, and 54.5-74.4 \% in cervical cancers. For patients with a malignant solid tumor, the death risk was higher for those with a HER3 ${ }^{+}$tumor than for those with a HER3- tumor (HR 1.60, 95\% CI: $1.27-2.02, P<0.001$ ). Subgroup analysis revealed this was also the case for patients with digestive or gastric cancer (HR $1.78, P<0.001 ;$ HR 2.18, $P<0.001)$. By contrast, HER3 had no prognostic significance in colorectal or breast cancer (HR 1.52, $P=0.296$; HR 1.23, $P=0.108$ ). HER3 $^{+}$is thus associated with poor survival in overall and in gastric cancer. The prognostic significance of HER3 ${ }^{+}$in other tumors is uncertain and deserves further study.
\end{abstract}

\section{INTRODUCTION}

Human epidermal growth factor receptor 3 (HER3, also known as erbB-3) is a distinctive member of the HER family, as it lacks certain residues that are essential for catalytic activity of other kinases. The function of HER3 was once considered to be passive and the clinical value of HER3 was greatly underestimated. However, in recent years, biochemical analysis confirmed that the kinase domain of HER3 was always "active" in the sense that it had a C-lobe that was competent to engage and activate the kinase domains of the other members of HER family [1]. Shi F's study also revealed that the intracellular region of HER3 was capable of binding ATP and promoting auto-phosphorylation [2]. The heterodimerization of HER3 with HER1/HER2/HER4 triggers the activation of signaling network, especially phosphatidylinositol 3-kinase / protein kinase B and downstream molecular, which is implicated in tumorigenesis, proliferation, migration and metastasis $[3,4]$.

With the deep understanding of the structure and function of HER3, the researches about the HER3 are carried out in full swing. HER3 has been verified to promote the tumor progression and metastasis $[5,6]$. The activation of HER3/phosphatidylinositol 3-kinase/protein kinase B signal pathway has led the targeted resistance in non-small-cell lung cancer, breast cancer and other tumors [7-10]. So much attention has focused on the strategies to inhibit the activity of HER3. The human HER3 monoclonal antibody KTN3379 inhibited tumor growth in divergent tumor models driven by either liganddependent or independent mechanisms in vitro and in vivo 
[11]. The novel anti-HER3 antibody patritumab abrogates cetuximab resistance mediated by heregulin in colorectal cancer cell [10]. The bispecific antibody MM-111 forms a trimeric complex with HER2 and HER3, effectively inhibiting the HER2/HER3 oncogenic unit and heregulininduced HER3 activation, showing antitumor activity [12]. The results of phase I study about anti-HER3 monoclonal antibody lumretuzumab and HER3/EGFR antibody MEHD7945A showed their good tolerance and the clinical benefits in patients with advanced cancer $[13,14]$.

In addition to the clinical development of anti-HER3 therapies, the predictive and prognostic significance of HER3 over-expression in malignant solid tumors is also the focus of clinical attention, but the research findings are contradictory. Some studies found that the positive presence of HER3 $\left(\mathrm{HER}^{+}\right.$) was associated with worse prognosis [1517], whereas others drew the opposite conclusions [18, 19]. Therefore, the present systematic analysis was performed to assess the prognostic significance of $\mathrm{HER}^{+}$in patients with malignant solid tumors.

\section{RESULTS}

\section{Selection of the trials}

In accordance with the search strategy (Figure 1), initially 3851 articles were considered. Screening of the primary title led to the exclusion of 3699 articles. In the remaining 152 articles, 109 articles were excluded for the following reasons: they were basic research rather than clinical study; there was no HER3-related survival analysis; or for other reasons. The full texts of the remaining 43 articles were screened, and 28 articles were excluded for the following reasons: the observed outcome was progression-free survival; the article contained only the result of univariate analysis; the method of detecting HER3 was reverse transcription polymerase chain reaction or fluorescence in situ hybridization; smaller samples led to a larger bias; or for other reasons. Finally, 15 articles were included (Table 1) [15-18, 20-30]. The PRISMA checklist is shown in Supplementary Table 1.

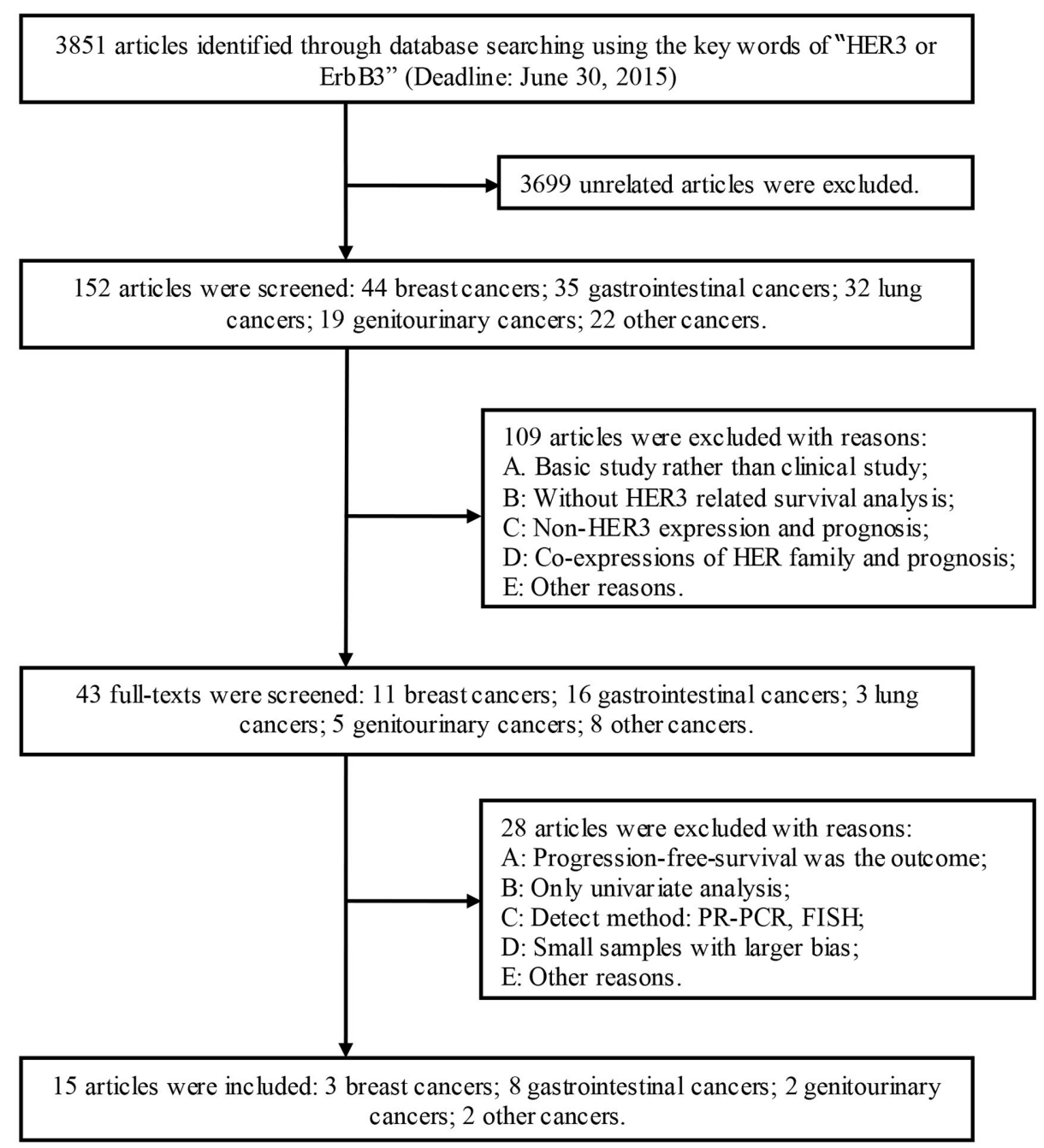

Figure 1: Schematic of the study selection. 
Table 1: Characteristics of the eligible studies included in the systematic assessment *

\begin{tabular}{|c|c|c|c|c|c|c|c|}
\hline First authors & Year & NOS & Tumor & $n$ & Follow-up & HER3 $^{+}, \%$ & IHC antibody \\
\hline Bae SY & 2013 & 9 & Breast cancer & 950 & $109.7 \mathrm{~m}(0.6-198.1)$ & 56.0 & $\begin{array}{c}\text { M7297, Dako, mouse } \\
\text { monoclonal }\end{array}$ \\
\hline Park YH & 2014 & 9 & Breast cancer & 109 & $36.0 \mathrm{~m}(12.0-72.5)$ & 30.3 & $\begin{array}{l}\text { M7297, Dako, mouse } \\
\text { monoclonal }\end{array}$ \\
\hline Sassen A & 2008 & 9 & Breast cancer & 173 & $125.6 \mathrm{~m}$ & 75.1 & 5A12, NanoTools \\
\hline Baiocchi G & 2009 & 8 & $\begin{array}{l}\text { Colorectal } \\
\text { cancer }\end{array}$ & 109 & $57.4 \mathrm{~m}(2.0-165.8)$ & 69.7 & $\begin{array}{l}\text { RB-9211, Lab Vision, } \\
\text { epitope specific rabbit } \\
\text { antibody }\end{array}$ \\
\hline Beji A & 2011 & 7 & $\begin{array}{l}\text { Colorectal } \\
\text { cancer }\end{array}$ & 110 & Not available & 74.5 & C-17, Santa Cruz \\
\hline Lédel F & 2014 & 8 & $\begin{array}{l}\text { Colorectal } \\
\text { cancer }\end{array}$ & 236 & Not available & 71.6 & $\begin{array}{l}\text { SP71, Abcam, rabbit } \\
\text { monoclonal }\end{array}$ \\
\hline Scartozzi M & 2012 & 7 & $\begin{array}{l}\text { Colorectal } \\
\text { cancer }\end{array}$ & 90 & Not available & 51.1 & $\begin{array}{l}\text { DAK-H3-IC, Dako, } \\
\text { mouse monoclonal }\end{array}$ \\
\hline Hayashi M & 2008 & 9 & Gastric cancer & 134 & $1943 d(50-3197)$ & 59.0 & $\begin{array}{l}\text { Mouse monoclonal } \\
\text { antibody, Neomarkers }\end{array}$ \\
\hline Li G & 2013 & 8 & Gastric cancer & 161 & $39.6 \mathrm{~m}$ & 55.9 & $\begin{array}{c}\text { Mouse antibody, } \\
\text { Shanghai Longisland } \\
\text { Biotec }\end{array}$ \\
\hline Zhang XL & 2009 & 8 & Gastric cancer & 102 & $8.0-30.0 \mathrm{~m}$ & 13.7 & $\begin{array}{c}\text { RTJ1, Beijing } \\
\text { Zhongshan Jinqiao } \\
\text { Biotechnology }\end{array}$ \\
\hline Hirakawa T & 2011 & 8 & $\begin{array}{l}\text { Pancreatic } \\
\text { cancer }\end{array}$ & 126 & $24.1 \mathrm{~m}(1.0-138.0)$ & 41.3 & $\begin{array}{c}\text { Antihuman HER3 } \\
\text { mouse monoclonal, } \\
\text { Nanotools }\end{array}$ \\
\hline Fuchs I & 2007 & 8 & $\begin{array}{l}\text { Cervical } \\
\text { carcinoma }\end{array}$ & 78 & $60.0 \mathrm{~m}(1.0-180.0)$ & 74.4 & Not mention \\
\hline Lee CM & 2005 & 7 & $\begin{array}{l}\text { Cervical } \\
\text { carcinoma }\end{array}$ & 55 & $24.0 \mathrm{~m}(1.0-227.0)$ & 54.5 & $\begin{array}{l}\text { MS-725-P, } \\
\text { NeoMarkers }\end{array}$ \\
\hline Reschke M & 2008 & 8 & Melanoma & 217 & $31.0-81.0 \mathrm{~m}$ & 55.3 & C-17, Santa Cruz. \\
\hline Takikita M & 2011 & 8 & $\begin{array}{l}\text { Head and neck } \\
\text { squamous cell } \\
\text { carcinoma }\end{array}$ & 378 & $1.0-180.0 \mathrm{~m}$ & 9.0 & $\begin{array}{l}\text { RTJ.2, Santa Cruz, } \\
\text { mouse monoclonal. }\end{array}$ \\
\hline
\end{tabular}

* Detection is IHC in all cases

\section{Main characteristics of the included studies}

A total of 2964 patients were included in the assessment (Table 1). There were 1168 patients with breast cancer, 545 with colorectal cancer, 397 with gastric cancer, 126 with pancreatic cancer, 378 with head and neck squamous cell carcinoma, 217 with melanoma, and 133 with cervical carcinoma. The rates of HER $3^{+}$were 30.3 $75.1 \%$ in breast cancers, $51.1-74.5 \%$ in colorectal cancers, $13.7-59.0 \%$ in gastric cancers, $54.5-74.4 \%$ in cervical carcinomas, $53.3 \%$ in melanomas, and $9.0 \%$ in head and neck squamous cell carcinomas (Figure 2). According to the Newcastle-Ottawa Scale (NOS) for quality, the scores of all the articles were 6 - 9 stars. The reagents used in the Immunohistochemistry (IHC) for HER3 and the definition of $\mathrm{HER}^{+}{ }^{+}$were described in Tables 1 and 2.

\section{The overall analysis of $\mathrm{HER3}^{+}$and survival time}

Fifteen articles reported the Hazard ratios (HRs) of $\mathrm{HER}^{+}$predicting overall survival (OS), gained through multivariate analysis. There was significant heterogeneity 
among the overall studies $(P=0.008)$, so the randomeffects model was applied. Considering HER $3^{+}$status as a risk factor predicting death, the risk of death in HER $3^{+}$ patients was 1.60 -fold than that of HER3 ${ }^{-}$patients (HR 1.60, 95\% Confidence intervals (CIs): $1.27-2.02, P<$ 0.001 ) (Figure 3). No significant publication bias was determined by the Begg's test or Egger's test $(P=0.092$, $P=0.337$, respectively; Figure 4).

In the sensitivity analysis, after removing one study with a large population [Bae SY 2013, $\mathrm{n}=816$ ], the risk of death in $\mathrm{HER}^{+}$patients was 1.78 -fold than that of HER3 ${ }^{-}$patients $(P<0.001)$. When a series of sensitivity analyses were conducted by deleting one set of data each time, no significant differences in the final results were observed.

The sub-analysis was done according to the diagnostic criteria and cutoff values of HER3 positive expression (Supplementary Figure 1). The risk of death in $\mathrm{HER}^{+}$patients was 1.30 -fold than that of HER3 ${ }^{-}$patients in subgroup I (95\%CI: $1.05-1.61, P<0.001)$; The risk of death in HER $3^{+}$patients was 1.91-fold than that of HER3 patients in subgroup II (95\%CI: $1.52-2.41, P<0.001)$; The risk of death in HER $3^{+}$patients was 2.52 -fold than that of HER3 $3^{-}$patients in subgroup III $(95 \% \mathrm{CI}$ : $1.59-$ 4.01, $P<0.001)$.

\section{Subgroup analysis of $\mathrm{HER3}^{+}$and survival time}

\section{Breast cancer}

Three articles concerned breast cancer. There was no significant heterogeneity among the studies $(P=0.211)$, so the fixed-effects model was applied. The HER $3^{+}$was not a risk factor predicting death in patients with breast cancer (HR 1.23, 95\%CI: $0.96-1.57, P=0.108$; Figure 5). No significant publication bias was determined by Begg's test or Egger's test (both $P>0.05$ ).

\section{Digestive tumors}

Eight articles concerned digestive tumors (4 colorectal, 3 gastric, and 1 pancreatic cancer). There was significant heterogeneity among these studies $(P<0.001)$, so the random-effects model was applied. Merged effects values showed that the risk of death in HER $3^{+}$patients was 1.78-fold than that of HER3- patients (HR 1.78, 95\%CI: $1.21-2.61, P<0.001$; Figure 6). No significant publication bias was determined by Begg's test and Egger's test (both $P>0.05$ ).

The gastric cancer subgroup analysis suggested that $\mathrm{HER}^{+}{ }^{+}$status was an excellent predictive risk factor for death (HR 2.18, 95\%CI: 1.45 - 3.27, $P<0.001$; Figure 5).

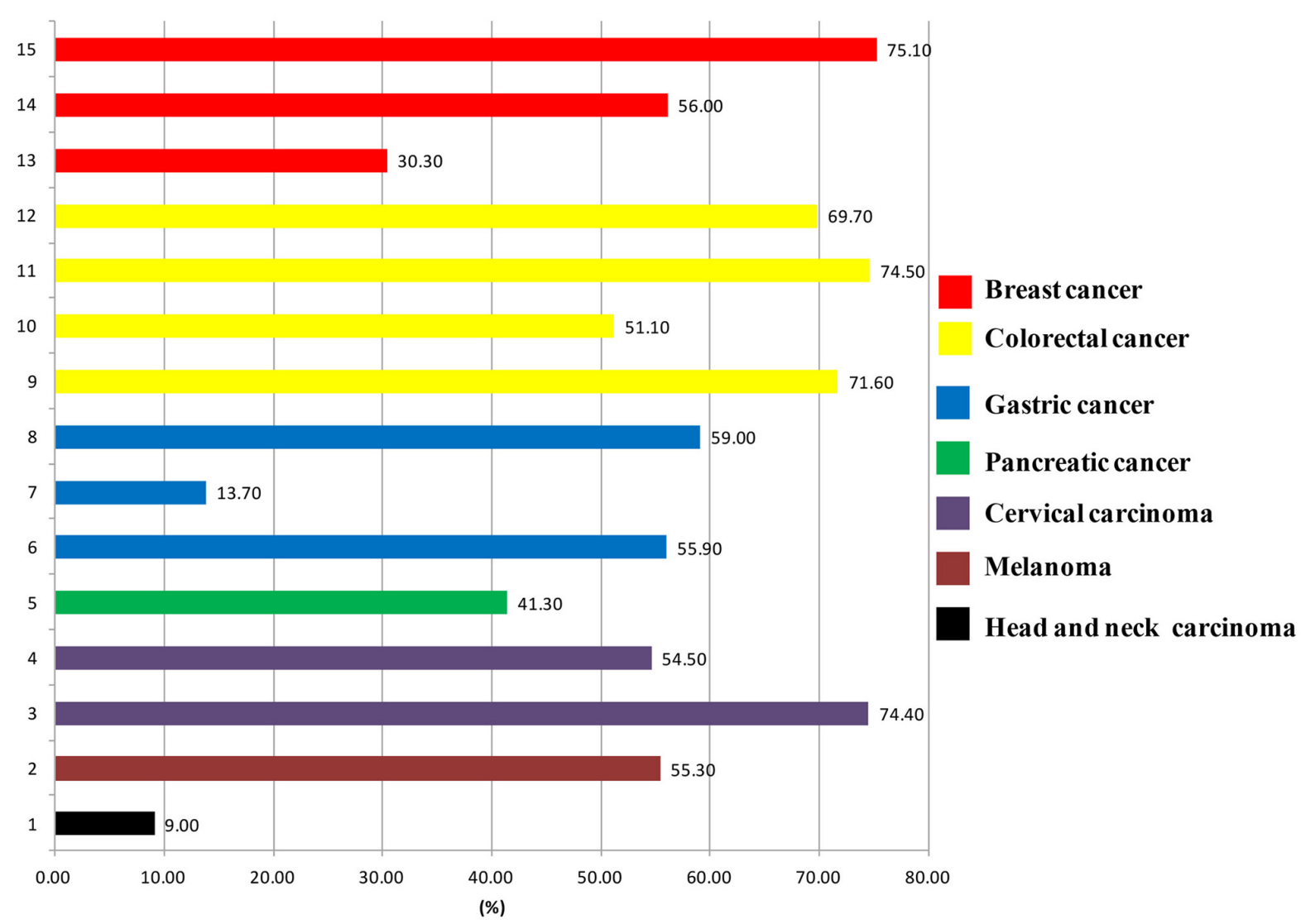

Figure 2: The positive rates of HER3 in different malignant solid tumors. 
Table 2: Definition of HER3 positive expression among the studies

\begin{tabular}{|c|c|c|c|}
\hline Authors & Tumor & subgroup & Definition of HER3 positive expression \\
\hline Bae SY & Breast & I & $\begin{array}{c}\text { HER3 staining was categorized by criteria } \mathrm{A}^{*} \text {. Negative }=\text { scores } 0 ; \\
\text { Positive }=\text { scores } 1+\operatorname{scores} 2+\text { and } 3+.\end{array}$ \\
\hline Park YH & Breast & I & $\begin{array}{c}\text { HER3 staining scored according to criteria } A^{*} \text {. Negative }=\text { scores } 0 ; \\
\text { Positive }=\operatorname{scores} 1+\operatorname{scores} 2+\text { and } 3+.\end{array}$ \\
\hline Sassen A & Breast & I & $\begin{array}{c}\text { HER3 staining scored according to criteria } A^{*} \text {. Negative }=\text { scores } 0 ; \\
\text { Positive }=\text { scores } 1+\text { scores } 2+\text { and } 3+.\end{array}$ \\
\hline Takikita M & $\begin{array}{l}\text { Head and neck } \\
\text { squamous cell } \\
\text { carcinoma }\end{array}$ & I & $\begin{array}{c}\text { HER3 staining scored according to criteria } A^{*} \text {. Negative }=\text { scores } 0 ; \\
\text { Positive }=\text { scores } 1+\text { scores } 2+\text { and } 3+.\end{array}$ \\
\hline Beji A & Colorectal & II & $\begin{array}{c}\text { HER3 staining was categorized by criteria } \mathrm{A}^{*} \text {. Negative }=\text { scores } 0 \text { and } \\
1+; \text { Positive }=\text { scores } 2+\text { and } 3+.\end{array}$ \\
\hline Lédel F & Colorectal & II & $\begin{array}{c}\text { HER3 staining was categorized by criteria } A^{*} \text {. Negative }=\text { scores } 0 \text { and } \\
1+; \text { Positive }=\text { scores } 2+\text { and } 3+.\end{array}$ \\
\hline Hayashi M & Gastric & II & $\begin{array}{c}\text { HER3 staining was categorized by criteria } A^{*} \text {. Negative }=\text { scores } 0 \text { and } \\
1+; \text { Positive }=\text { scores } 2+\text { and } 3+.\end{array}$ \\
\hline Li G & Gastric & II & $\begin{array}{c}\text { HER3 staining was categorized by criteria } A^{*} \text {. Negative }=\text { scores } 0 \text { and } \\
1+; \text { Positive }=\text { scores } 2+\text { and } 3+.\end{array}$ \\
\hline Zhang XL & Gastric & II & $\begin{array}{c}\text { HER3 staining was categorized by criteria } A^{*} . \text { Negative }=\text { scores } 0 \text { and } \\
1+; \text { Positive }=\text { scores } 2+\text { and } 3+.\end{array}$ \\
\hline Hirakawa T & Pancreatic & II & $\begin{array}{c}\text { HER3 staining was categorized by criteria } A^{*} \text {. Negative }=\text { scores } 0 \text { and } \\
1+; \text { Positive }=\text { scores } 2+\text { and } 3+.\end{array}$ \\
\hline Lee CM & Cervical & II & HER 3 negative $=$ scores 0 and $1+$; HER 3 positive: $=$ scores $2+$ and $3+$. \\
\hline Fuchs I & Cervical & III & $\begin{array}{c}\text { HER3 negative } \leq 3 ; \text { HER3 positive }>3 . \text { Score }=\text { positive cells }(0, \\
\text { negative; } 1,1-10 \% ; 2,11 \%-50 \% ; 3,51 \%-80 \% ; 4,>80 \%) \times \text { staining } \\
\text { intensity }(0-3) .\end{array}$ \\
\hline Reschke M & Melanoma & III & $\begin{array}{c}\text { HER3 negative } \leq 6 ; \text { HER3 positive }>6 . \text { Score }=\text { positive cells }(0, \\
\text { negative; } 1,1-10 \% ; 2,11 \%-50 \% ; 3,51 \%-80 \% ; 4,>80 \%) \times \text { staining } \\
\text { intensity }(0-3) .\end{array}$ \\
\hline Scartozzi M & Colorectal & III & $\begin{array}{l}\text { HER3 negative } \leq 8 ; \text { HER3 positive }>8 \text {. Score }=\text { positive cells }(0,<10 \% \\
1,10-25 \% ; 2,26-50 \% ; 3,51-75 \% ; 4,>75 \%) \times \text { staining intensity }(0-3)\end{array}$ \\
\hline Baiocchi G & Colorectal & IV & $\begin{array}{c}\text { HER3 negative } \leq 1.5 ; \text { HER3 positive } 1.5-3 . \text { Score }=[\text { The cytoplasmic } \\
\text { staining }(0-3)+\text { The membranous staining }(0-3)] / \text { the numbers of tumor } \\
\text { cores evaluated. }\end{array}$ \\
\hline
\end{tabular}

${ }^{*}$ Criteria A. HER3 staining was categorized by intensity as $0,1+, 2+$, and $3+.0$, samples with no staining at all, or in $<10$ $\%$ of the tumor cells; $1+$, a faint or barely perceptible incomplete staining in $>10 \%$ of tumor cells; $2+$, weak-to-moderate staining in $>10 \%$ of tumor cells; $3+$, strong staining in $>10-30 \%$ of tumor cells.

No significant publication bias was determined by Begg's test and Egger's test (both $P>0.05$ ).

The colorectal subgroup analysis showed that $\mathrm{HER}^{+}{ }^{+}$status was not a predictive risk factor for death (HR 1.52, 95\%CI: 0.69 - 3.33, $P=0.296$; Figure 5). No significant publication bias was determined by Begg's test and Egger's test (both $P>0.05$ ).

\section{DISCUSSION}

The systematic analysis showed that HER3 positive expression was associated with worse OS in patients with malignant solid tumors, the risk of death in HER3 ${ }^{+}$ patients was 1.60 -fold than that of HER3- ${ }^{-}$patients in the overall analysis $(P<0.001)$. The systematic analysis of Ocana A [31] drew similar conclusions by way of different statistical indicators, i.e., HER $3^{+}$was associated with worse OS at both 3 years and 5 years. Our study analyzed the data obtained by unified detection method and the HRs calculated through multivariate analysis, and our study had a larger sample of patients and a longer follow-up time, therefore, the result was more convincing. Our result was supported by the sensitivity analyses, which confirmed the high stability and reliability of the overall research. 


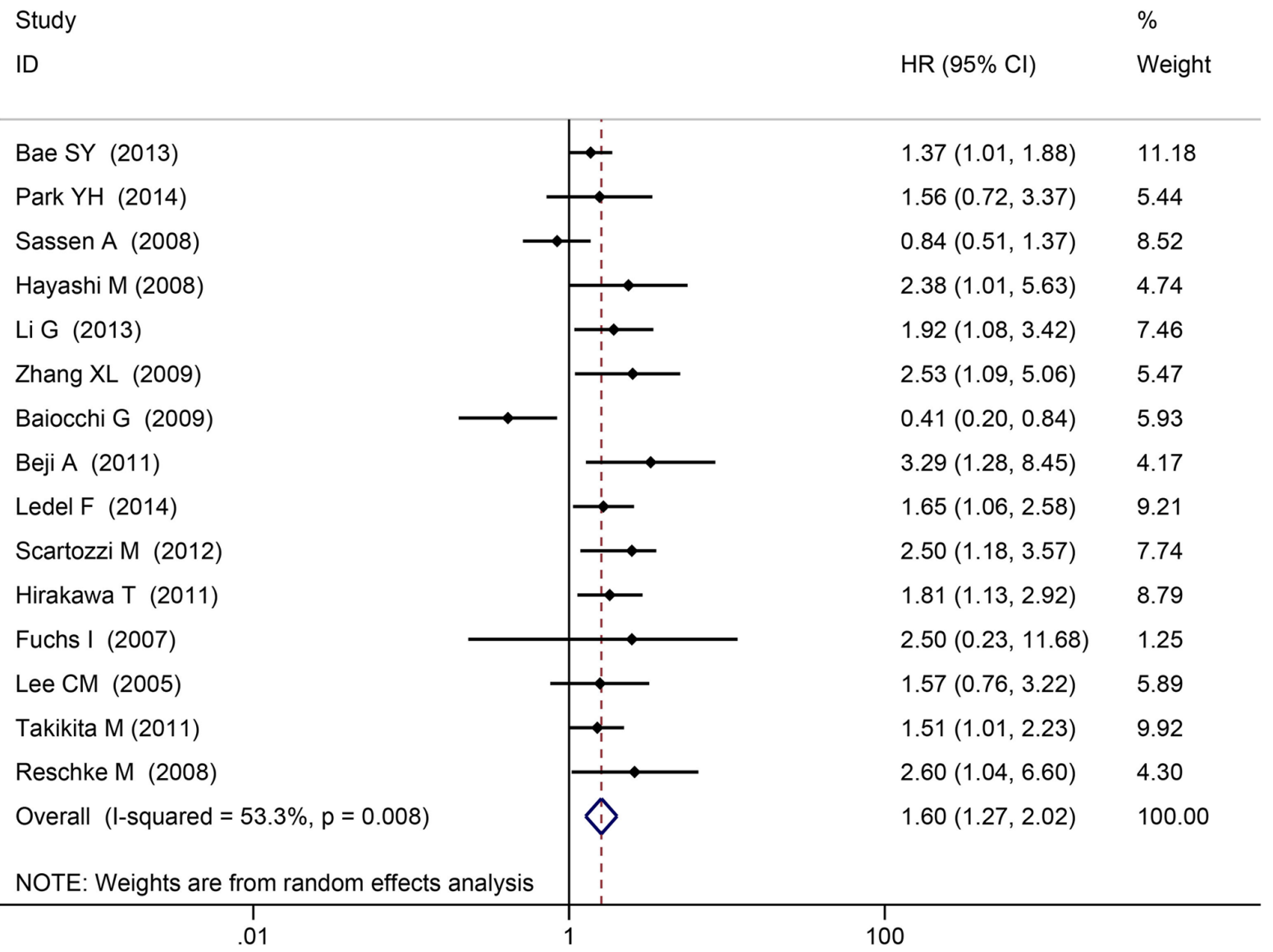

Figure 3: The overall analysis of $\mathrm{HER}^{+}$and survival time.
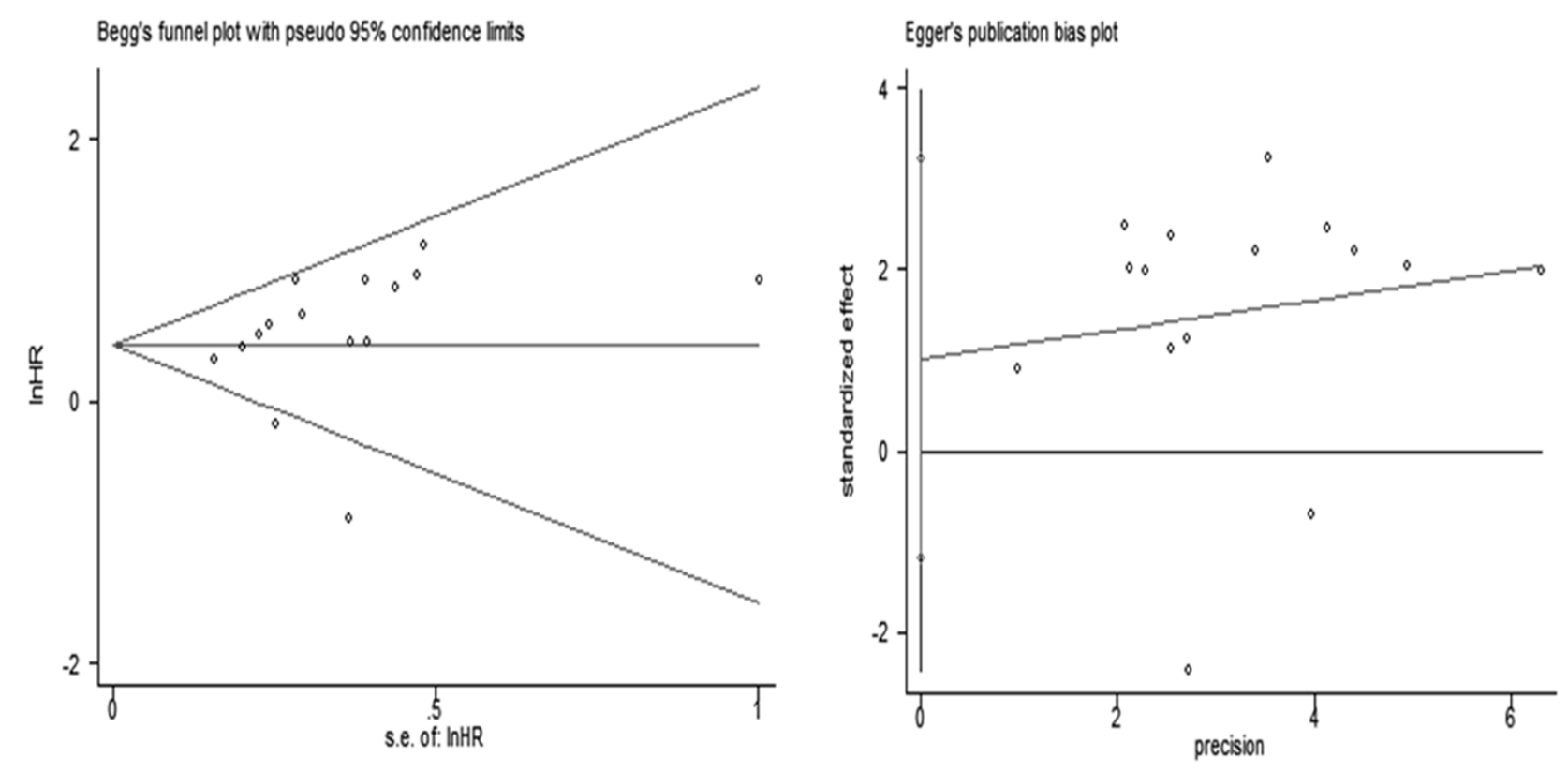

Figure 4: The Begg's test and Egger's test for the overall analysis. 
Subgroup analysis according to diagnostic criteria and cutoff value obtained the similar conclusion with the overall analysis.

Breast cancer is a highly heterogeneous disease [32] and the prognostic value of HER3 seems to be uncertain. Previous studies reported that $\mathrm{HER}^{+}$was associated with established prognostic indicators, such as higher histological grading [33] and primary breast tumors larger than $2 \mathrm{~cm}$ [34]. Giltnane JM found that the high-HER3 group had a $53 \% 10$-year survival compared to $69 \%$ in the low-HER3 group $(P<0.001)$ [35]. Berghoff AS reported HER3-overexpression was not correlated with OS, time to brain metastases in the whole population, but negative correlation was observed in the HER2-positive subgroup population [36]. However, Sassen A reported the expression status of HER3 was not associated with survival time [20]. In 2015, Hellenic Cooperative Oncology Group validation study reported that the combination of high EGFR, high HER2, low HER3 and low HER4 mRNA expression was associated with a trend for shorter OS and significantly worse disease-free survival in high-risk early breast cancer patients [37]. Knowlden JM reported that HER3mRNA expression was associated with improved OS as well as estrogen receptor, which is a favorable prognostic factor for breast cancer [38]. In our subgroup analysis of breast cancer, the HER ${ }^{+}$ rates was $30-75 \%$, the risk of death in the HER $3^{+}$group was not significantly higher than that of the HER $3^{-}$group.

In our systematic analysis of digestive tumor, the risk of death in $\mathrm{HER}^{+}$patients was significantly increased than that of HER ${ }^{-}$patients $(P<0.001)$. The HER2/HER3 heterodimer is considered the most active oncogenic unit, and HER3 is a crucial factor in HER2-mediated tumor cell growth and proliferation [39]. HER3 seems to have the similar prognostic value as HER2. Wang S's meta-analysis showed that HER2 ${ }^{+}$status was related to poor prognosis of gastric cancer (HR 1.58, P<0.001) [40]. Begnami et al.'s study showed that both HER2 and HER3 are predictors of poor outcome in gastric carcinomas [41]. In our gastric cancer subgroup analysis, HER $3^{+}$status was associated with the poor outcome (HR 2.18, $P<0.001$ ).

There is almost no HER3 expression in normal colon tissue. However, the $\mathrm{HER}^{+}$rate in colorectal cancer tissue is up to $51-75 \%$. Conclusions regarding the value of HER3 for predicting clinical outcome of colorectal cancer were contradictory [18, 22, 42]. Kapitanovic S reported that the median survival time of patients with HER3- (181.1 wk) was significantly longer than that of patients with HER3 ${ }^{+}$(113.9 wk) [42]. In Beji A's study, the strong presence of membranous HER3 indicated a higher risk of tumor-associated death (HR 3.29, $P<0.05$ ), establishing HER3 as a putative novel independent prognostic marker for colorectal cancer [22]. In wild-type Kirsten Ras (KRAS) colorectal cancer patients treated with cetuximab, the median progression-free survival and OS were 6.3 and 13.6 months in the HER3 ${ }^{-}$group, 2.8 and 10.5 months in the $\mathrm{HER}^{+}$group, HER3 ${ }^{+}$seemed to be a negative prognostic factor in wild-type KRAS colorectal cancer patients, the combined analysis of HER3 and KRAS
Study

ID

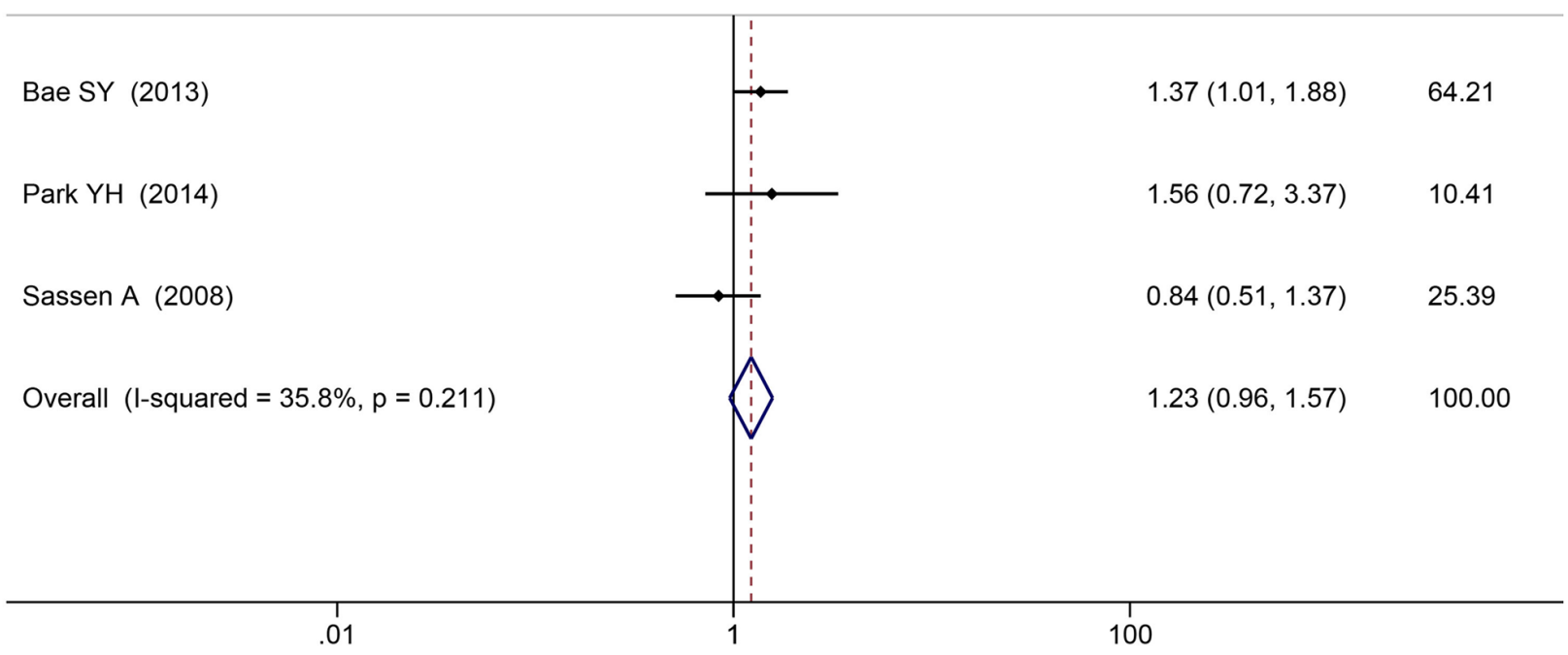

$\%$

$\mathrm{HR}(95 \% \mathrm{Cl}) \quad$ Weight

Figure 5: Breast cancer subgroup analysis of $\mathrm{HER3}^{+}$and survival time. 
might be an effective strategy for better selection of responding colorectal cancer patients [23]. Lédel F reported $\mathrm{HER} 3^{+}$was an independent negative prognostic factor for OS in the entire population of colorectal cancer patients and in the subgroup with colon cancer stage II, but not in stage III [16], it indicated that $\mathrm{HER}^{+}$status was not strong as a prognostic factor, and the prognostic value decreased when dividing the patients into subgroups. He later reported that HER $3^{+}$ status correlated to shorter disease-free survival in the patients with distal colon cancer (HR 0.56, $P<0.05)$ [43]. On the contrary, Baiocchi G's results showed that
HER $^{-}$status was an independent prognostic factor for lower survival; the 5-year survival rates were $51.5 \%$ in $\mathrm{HER}^{-}$patients and $77.6 \%$ in $\mathrm{HER}^{+}$patients [18]. In our present colorectal cancer subgroup analysis, HER $3^{+}$ was not significantly associated with the OS (HR 1.52, $P=0.296)$.

We obtained positive result from the whole analysis of malignant solid tumor and subgroup analysis of digestive tumor and gastric cancer. However, the subanalysis of breast cancer and colorectal cancer didn't show the expected positive conclusions. Summing up the characteristics in subgroup, the differences in clinical

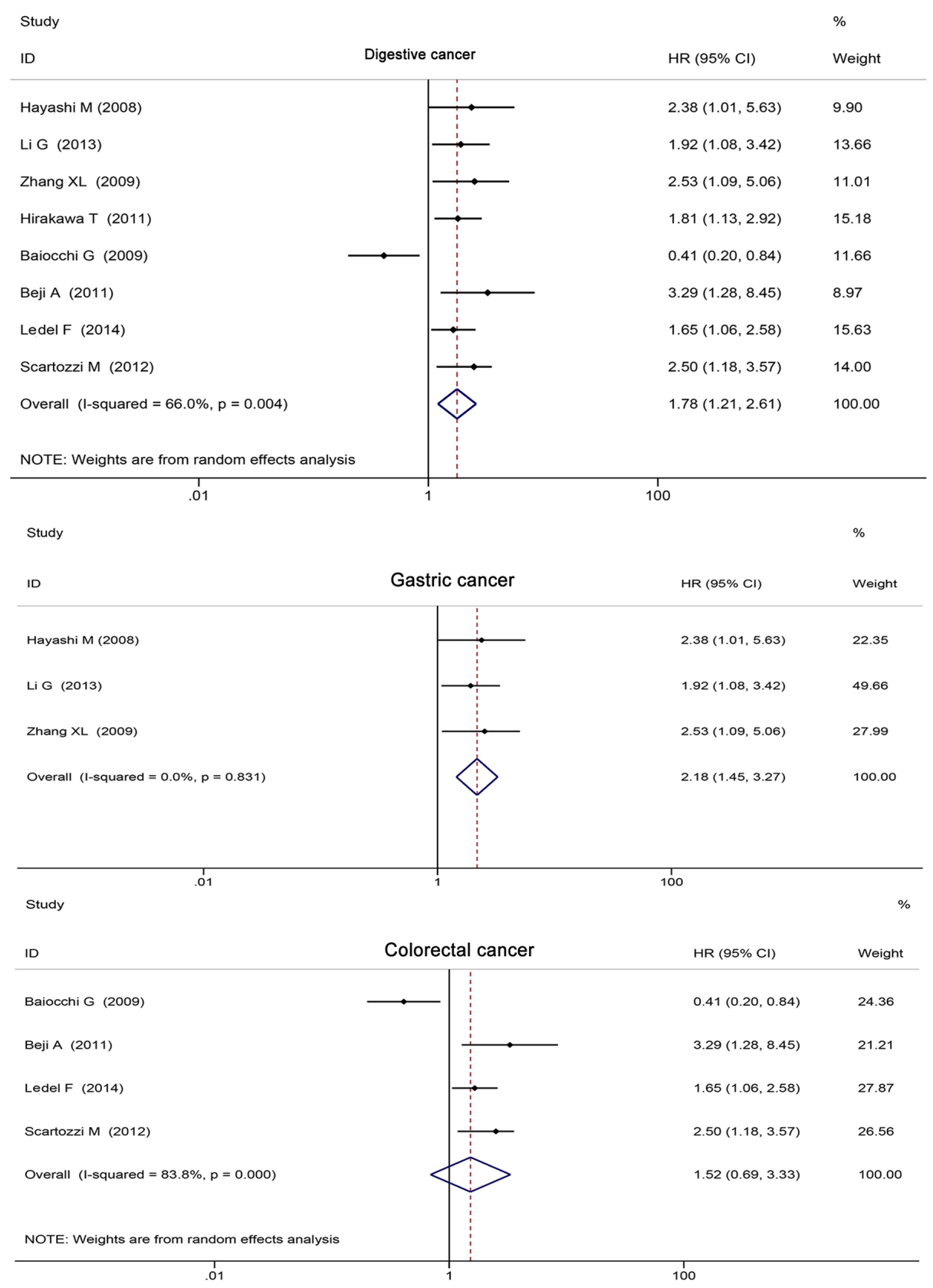

Figure 6: Digestive tumors subgroup analysis of $\mathrm{HER3}^{+}$and survival. 
staging, sample sizes, IHC antibody used and others might prevent investigators from reaching definitive conclusions. Of course, the differences of HER2 status and hormone receptor status in breast cancer, lesion sites and KRAS status in colorectal cancer, make the related subgroup analysis very challenging. Further hierarchical analysis was needed.

In all included articles, only the results obtained by IHC and multivariate analysis were using for systematic analysis. Although reverse-transcription polymerase chain reaction, fluorescence in situ hybridization, and VeraTag have relatively higher sensitivity and specificity, but these testing methods are not be routinely applied in clinical practice [44-48], and the mixed analysis of HER3 expression detected by different methods might bring more bias, therefore, only the results of IHC were considered. To avoid the bias caused by numerous clinical factors, studies reporting HRs for HER3 predicting OS via multivariate analysis were included. Despite all the efforts, the analysis still has limitations. First, all included articles are defined as high quality with NOS of $7-9$, however, the literature-based analysis is compromised by the potential for publication bias. Second, there is no standardized method and consensus diagnostic threshold to evaluate HER3 expression currently. Therefore, the substantial heterogeneity could not be fully compensated by applying the random-effects model. An internationally standardized diagnostic method is urgently needed. However, IHC is the most feasible and most reliable method for assessing the HER3 expression.

$\mathrm{HER}^{+}$is associated with the poor survival in the overall analysis and gastric cancer subgroup analysis, however, the prognostic significance of it in other tumors are uncertain and deserves further study. However, interactions among ligand, HER3, HER family members and downstream signaling molecules are intricate, the predicting significance of HER-related signaling molecular co-expression pattern should be taken into account. The inherent diversity and complexity of each tumor maybe influence the precise of the result, and stratified studies should be encouraged. Of course, unified detection method and reagent, and standardized diagnosis criteria will provide the best support for determining the prognostic value of HER3 positive expression in malignant solid tumors.

\section{MATERIALS AND METHODS}

\section{Literature search strategy}

The systematic analysis was performed in accordance with the criteria of the Preferred Reporting Items for Systematic Reviews and Meta-analyses (PRISMA) [49]. The databases PubMed, Embase and CNKI were searched for articles reporting the prognostic significance of HER3. Original articles written in English or Chinese and published on or before 30 Dec 2015 were collected.
To ensure that all relevant articles were reviewed, the references of articles on associations between members of the epidermal growth factor receptor family and prognosis were manually screened. The initial search used the MeSH terms: "HER3 OR erbB 3 OR Receptor, erbB 3 OR erbB-3 Receptor OR c-erbB-3 Protein OR c erbB 3 Protein OR erbB-3 Protein OR erbB 3 Protein" AND "Neoplasm OR Neoplasia OR Tumor OR Tumors OR Cancer OR Cancers".

\section{Inclusion criteria and category}

All the articles reporting the HRs for HER3 ${ }^{+}$ predicting overall survival using multivariate analysis were included in the systematic assessment. All the articles detected HER 3 via IHC. The diagnostic criteria and cutoff of HER $3^{+}$expression were depicted and summarized in Table 2. The diagnostic criteria were divided into three categories, and the cutoff values were divided into four categories. (1). HER $3^{+}$was categorized by staining intensity as $0,1+, 2+$, and $3+.0$, samples with no staining at all, or in $<10 \%$ of the tumor cells; $1+$, a faint or barely perceptible incomplete staining in $>10 \%$ of tumor cells; $2+$, weak-to-moderate staining in $>10 \%$ of tumor cells; $3+$, strong staining in $>10-30 \%$ of tumor cells. One cutoff value was "Negative $=$ scores 0 ; Positive $=$ scores $1+$ scores 2+ and 3+"; another cutoff value was "Negative = scores 0 and $1+$; Positive $=$ scores $2+$ and $3+$ ". (2). HER $3^{+}$ was categorized by "the percentages of positive cells $\times$ staining intensity". (3). HER3 ${ }^{+}$was categorized by "(the cytoplasmic staining + the membranous staining)/ the numbers of tumor cores evaluated". The patients were classified into subgroup I, II, III, IV according to the diagnostic criteria and the cutoff values. (Table 2)

\section{Data extraction}

All likely abstracts were assessed independently by two investigators (Qin Li and Peng-fei Zhao) based on the predefined inclusion criteria. If only one investigator considered an abstract eligible, the full text of the article was retrieved and reviewed in detail by both investigators. Any discrepancy was resolved by an arbiter (Rui-xue Zhang) or by contacting the authors of the original article.

The survival data and HRs were extracted from original articles. The following were recorded: authors' names, journal title, year of publication, tumor types, follow-up time, antibody used for the detection, the HER3 examination method and scoring protocol, number and ratio of $\mathrm{HER}^{+}$, and the cutoff value for defining $\mathrm{HER}^{+}$ (Table 1 and Table 2).

\section{Assessment of methodological quality}

The quality of the studies was assessed independently by two researchers (Qin Li and Peng-fei Zhao), using the NOS (http://www.ohri.ca/programs/clinical_epidemiology/ 
oxford.asp). In these observational studies, the assessment included selection of cases, comparability of the cohorts with regard to design or analysis, and outcomes. Studies with a total NOS score of 5 - 9 were defined as high quality, whereas a score 0 - 4 was defined as low quality.

\section{Statistical analysis}

The statistical analyses were carried out using Stata version 11.0 (StataCorp LP, Texas, USA). Heterogeneity was investigated using Cochrane's Q-test and $\mathrm{I}^{2}$ statistics. $P>0.1$ and $\mathrm{I}^{2}<50 \%$ was considered lack of heterogeneity among the studies, and the pooled estimation of HR for each study was calculated according to the fixed-effects model (Mantel-Haenszel method). $P<0.1$ and $\mathrm{I}^{2}>50 \%$ indicated that the studies were heterogeneous, and then the random-effects model (DerSimonian-Laird method) was applied. The HRs was the principal measures of effect and was presented with $95 \%$ CIs. All reported $P$ values were from two-sided versions of the respective tests. $P<0.05$ was considered statistically significant. Sensitivity analyses were also conducted, the changes of the combined effects were observed by excluding studies with large samples or by removing a set of research data one at a time. Publication and selection biases were investigated through funnel plots based on Egger's and Begg's tests [50, 51].

\section{Abbreviations}

Human epidermal growth factor receptor 3: HER3; Newcastle-Ottawa Scale: NOS; Immunohistochemistry: IHC;

Hazard ratios: HRs;

Overall survival: OS;

Confidence intervals: CIs;

Wild-type Kirsten Ras: KRAS.

\section{Author contributions}

Q.L. and B.W.C. designed experiments; H.Y. and H.W. developed methodology; R.X.Z., P.F.Z. and T.L. collected data; H.Y. and L.W. analyzed data; Q.L. wrote the manuscript.

\section{ACKNOWLEDGMENTS}

We thank the Wu Shanshan for statistical support.

\section{CONFLICTS OF INTEREST} interest.

The authors have declared no conflicts of financial

\section{FUNDING}

This work was supported by National Natural Science Foundation of China (Grant NO. 81301912 and 81272615),
Beijing Municipal Health System High-level Health Person Foundation Project (Grant NO. 2014-3-005), Beijing Municipal Science and Technology Commission (Capital Features, Z161100000516083, to Qin Li).

\section{REFERENCES}

1. Jura N, Shan Y, Cao X, Shaw DE, Kuriyan J. Structural analysis of the catalytically inactive kinase domain of the human EGF receptor 3. Proc Natl Acad Sci U S A. 2009; 106: 21608-21613.

2. Shi F, Telesco SE, Liu Y, Radhakrishnan R, Lemmon MA. ErbB3/HER3 intracellular domain is competent to bind ATP and catalyze autophosphorylation. Proc Natl Acad Sci U S A. 2010; 107: 7692-7267.

3. Smirnova T, Zhou ZN, Flinn RJ, Wyckoff J, Boimel PJ, Pozzuto M, Coniglio SJ, Backer JM, Bresnick AR, Condeelis JS, Hynes NE, Segall JE. Phosphoinositide 3-kinase signaling is critical for ErbB3-driven breast cancer cell motility and metastasis. Oncogene. 2012; 31: 706-715.

4. Vivanco I, Sawyers CL. The phosphatidylinositol 3-Kinase AKT pathway in human cancer. Nat Rev Cancer. 2002; 2: 489-501.

5. Lakshmanan I, Seshacharyulu P, Haridas D, Rachagani S, Gupta S, Joshi S, Guda C, Yan Y, Jain M, Ganti AK, Ponnusamy MP, Batra SK. Novel HER3/MUC4 oncogenic signaling aggravates the tumorigenic phenotypes of pancreatic cancer cells. Oncotarget. 2015; 6: 21085-21099. doi: 10.18632/oncotarget.3912.

6. Wu X, Chen Y, Li G, Xia L, Gu R, Wen X, Ming X, Chen H. Her3 is associated with poor survival of gastric adenocarcinoma: Her3 promotes proliferation, survival and migration of human gastric cancer mediated by PI3K/AKT signaling pathway. Med Oncol. 2014; 31: 903.

7. Sergina NV, Rausch M, Wang D, Blair J, Hann B, Shokat KM, Moasser MM. Escape from HER-family tyrosine kinase inhibitor therapy by the kinase-inactive HER3. Nature. 2007; 445: 437-441.

8. Erjala K, Sundvall M, Junttila TT, Zhang N, Savisalo M, Mali P, Kulmala J, Pulkkinen J, Grenman R, Elenius K. Signaling via ErbB2 and ErbB3 associates with resistance and epidermal growth factor receptor (EGFR) amplification with sensitivity to EGFR inhibitor gefitinib in head and neck squamous cell carcinoma cells. Clin Cancer Res. 2006; 12: 4103-4111.

9. Engelman JA, Zejnullahu K, Mitsudomi T, Song Y, Hyland C, Park JO, Lindeman N, Gale CM, Zhao X, Christensen J, Kosaka T, Holmes AJ, Rogers AM, et al. MET amplification leads to gefitinib resistance in lung cancer by activating ERBB3 signaling. Science. 2007; 316: 1039-1043.

10. Kawakami H, Okamoto I, Yonesaka K, Okamoto K, Shibata K, Shinkai Y, Sakamoto H, Kitano M, Tamura T, Nishio $\mathrm{K}$, Nakagawa K. The anti-HER3 antibody patritumab abrogates cetuximab resistance mediated by heregulin in 
colorectal cancer cells. Oncotarget. 2014; 5: 11847-11856. doi: 10.18632/oncotarget.2663.

11. Xiao Z, Carrasco RA, Schifferli K, Kinneer K, Tammali R, Chen H, Rothstein R, Wetzel L, Yang C, Chowdhury P, Tsui P, Steiner P, Jallal B, et al. A Potent HER3 Monoclonal Antibody That Blocks Both Ligand-Dependent and -Independent Activities: Differential Impacts of PTEN Status on Tumor Response. Mol Cancer Ther. 2016; 15: 689-701.

12. McDonagh CF, Huhalov A, Harms BD, Adams S, Paragas V, Oyama S, Zhang B, Luus L, Overland R, Nguyen S, Gu J, Kohli N, Wallace M, et al. Antitumor activity of a novel bispecific antibody that targets the ErbB2/ErbB3 oncogenic unit and inhibits heregulin-induced activation of ErbB3. Mol Cancer Ther. 2012; 11: 582-593.

13. Meulendijks D, Jacob W, Martinez-Garcia M, Taus A, Lolkema MP, Voest EE, Langenberg MH, Fleitas KT, Cervantes A, De Jonge MJ, Sleijfer S, Soerensen MM, Thomas M, et al. First-in-Human Phase I Study of Lumretuzumab, a Glycoengineered Humanized AntiHER3 Monoclonal Antibody, in Patients with Metastatic or Advanced HER3-Positive Solid Tumors. Clin Cancer Res. 2016; 22: 877-885.

14. Juric D, Dienstmann R, Cervantes A, Hidalgo M, Messersmith W, Blumenschein GR, Tabernero J, Roda D, Calles A, Jimeno A, Wang X, Bohórquez SS, Leddy $\mathrm{C}$, et al. Safety and Pharmacokinetics/Pharmacodynamics of the First-in-Class Dual Action HER3/EGFR Antibody MEHD7945A in Locally Advanced or Metastatic Epithelial Tumors. Clin Cancer Res. 2015; 21: 2462-2470.

15. Bae SY, La Choi Y, Kim S, Kim M, Kim J, Jung SP, Choi MY, Lee SK, Kil WH, Lee JE, Nam SJ. HER3 status by immunohistochemistry is correlated with poor prognosis in hormone receptor-negative breast cancer patients. Breast Cancer Res Treat. 2013; 139: 741-750.

16. Lédel F, Hallström M, Ragnhammar P, Öhrling K, Edler D. HER3 expression in patients with primary colorectal cancer and corresponding lymph node metastases related to clinical outcome. Eur J Cancer. 2014; 50: 656-662.

17. Zhang XL, Yang YS, Xu DP, Qu JH, Guo MZ, Gong Y, Huang J. Comparative study on overexpression of HER2/ neu and HER3 in gastric cancer. World J Surg. 2009; 33: 2112-2118.

18. Baiocchi G, Lopes A, Coudry RA, Rossi BM, Soares FA, Aguiar S, Guimarães GC, Ferreira FO, Nakagawa WT. ErbB family immunohistochemical expression in colorectal cancer patients with higher risk of recurrence after radical surgery. Int J Colorectal Dis. 2009; 24: 1059-1068.

19. Memon AA, Sorensen BS, Melgard P, Fokdal L, Thykjaer T, Nexo E. Expression of HER3, HER4 and their ligand heregulin-4 is associated with better survival in bladder cancer patients. Br J Cancer. 2004; 91: 2034-2041.

20. Sassen A, Rochon J, Wild P, Hartmann A, Hofstaedter F, Schwarz S, Brockhoff G. Cytogenetic analysis of HER1/
EGFR, HER2, HER3 and HER4 in 278 breast cancer patients. Breast Cancer Res. 2008; 10: R2.

21. Park YH, Jung HA, Choi MK, Chang W, Choi YL, Do IG, Ahn JS, Im YH. Role of HER3 expression and PTEN loss in patients with HER2-overexpressing metastatic breast cancer (MBC) who received taxane plus trastuzumab treatment. $\mathrm{Br}$ J Cancer. 2014; 110: 384-391.

22. Beji A, Horst D, Engel J, Kirchner T, Ullrich A. Toward the prognostic significance and therapeutic potential of HER3 receptor tyrosine kinase in human colon cancer. Clin Cancer Res. 2012; 18: 956-968.

23. Scartozzi M, Giampieri R, Maccaroni E, Mandolesi A, Giustini L, Silva R, Zaniboni A, Biscotti T, Biagetti S, Galizia E, Loupakis F, Falcone A, Bearzi I, et al. Analysis of HER-3, insulin growth factor-1, nuclear factor-kB and epidermal growth factor receptor gene copy number in the prediction of clinical outcome for K-RAS wild-type colorectal cancer patients receiving irinotecan-cetuximaab. Ann Oncol. 2012; 23: 1706-1712.

24. Hayashi M, Inokuchi M, Takagi Y, Yamada H, Kojima K, Kumagai J, Kawano T, Sugihara K. High expression of HER3 is associated with a decreased survival in gastric cancer. Clin Cancer Res. 2008; 14: 7843-7849.

25. Li G, Gu RM, Wen X, Ming XZ, Xia L, Xu XY, Zhang J, Chen HQ. Clinical significance of human epidermal growth factor receptor family molecules expression in gastric cancer. Zhonghua Wei Chang Wai Ke Za Zhi. 2013; 16: 668-672.

26. Hirakawa T, Nakata B, Amano R, Kimura K, Shimizu S, Ohira G, Yamada N, Ohira, Hirakawa K. HER3 overexpression as an independent indicator of poor prognosis for patients with curatively resected pancreatic cancer. Oncology. 2011; 81: 192-198.

27. Lee CM, Shrieve DC, Zempolich KA, Lee RJ, Hammond E, Handrahan DL, Gaffney DK. Correlation between human epidermal growth factor receptor family (EGFR, HER2, HER3, HER4), phosphorylated Akt (P-Akt), and clinical outcomes after radiation therapy in carcinoma of the cervix. Gynecol Oncol. 2005; 99: 415-421.

28. Fuchs I, Vorsteher N, Bühler H, Evers K, Sehouli J, Schaller $\mathrm{G}$, Kümmel $\mathrm{S}$. The prognostic significance of human epidermal growth factor receptor correlations in squamous cell cervical carcinoma. Anticancer Res. 2007; 27: 959-963.

29. Reschke M, Mihic-Probst D, van der Horst EH, Knyazev P, Wild PJ, Hutterer M, Meyer S, Dummer R, Moch H, Ullrich A. HER3 is a determinant for poor prognosis in melanoma. Clin Cancer Res. 2008; 14: 5188-5197.

30. Takikita M, Xie R, Chung JY, Cho H, Ylaya K, Hong SM, Moskaluk CA, Hewitt SM. Membranous expression of Her3 is associated with a decreased survival in head and neck squamous cell carcinoma. J Transl Med. 2011; 9: 126. 
31. Ocana A, Vera-Badillo F, Seruga B, Templeton A, Pandiella A, Amir E. HER3 overexpression and survival in solid tumors: a meta-analysis. J Natl Cancer Inst. 2013; 105: 266-273.

32. Senkus E, Kyriakides S, Penault-Llorca F, Poortmans P, Thompson A, Zackrisson S, Cardoso F. Primary breast cancer: ESMO Clinical Practice Guidelines for diagnosis, treatment and follow-up. Ann Oncol. 2013; 24: vi7-23.

33. Naidu R, Yadav M, Nair S, Kutty MK. Expression of c-erbB3 protein in primary breast carcinomas. Br J Cancer. 1998; 78: 1385-1390.

34. Travis A, Pinder SE, Robertson JF, Bell JA, Wencyk P, Gullick WJ, Nicholson RI, Poller DN, Blamey RW, Elston CW, Ellis IO. C-erbB-3 in human breast carcinoma: expression and relation to prognosis and established prognostic indicators. Br J Cancer. 1996; 74: 229-233.

35. Giltnane JM, Moeder CB, Camp RL, Rimm DL. Quantitative multiplexed analysis of ErbB family coexpression for primary breast cancer prognosis in a large retrospective cohort. Cancer. 2009; 115: 2400-2409.

36. Berghoff AS, Bartsch R, Preusser M, Ricken G, Steger GG, Bago-Horvath Z, Rudas M, Streubel B, Dubsky P, Gnant M, Fitzal F, Zielinski CC, Birner P. Co-overexpression of HER2/HER3 is a predictor of impaired survival in breast cancer patients. Breast. 2014; 23: 637-643.

37. Koutras A, Kalogeras KT, Wirtz RM, Alexopoulou Z, Bobos M, Zagouri F, Veltrup E, Timotheadou E, Gogas H, Pentheroudakis G, Pisanidis N, Magkou C, Christodoulou $\mathrm{C}$, et al. Evaluation of the prognostic significance of HER family mRNA expression in high-risk early breast cancer: a Hellenic Cooperative Oncology Group (HeCOG) validation study. J Transl Med. 2015; 13: 171.

38. Knowlden JM, Gee JM, Seery LT, Farrow L, Gullick WJ, Ellis IO, Blamey RW, Robertson JF, Nicholson RI. c-erbB3 and c-erbB4 expression is a feature of the endocrine responsive phenotype in clinical breast cancer. Oncogene. 1998; 17: 1949-1957.

39. Hsieh AC, Moasser MM. Targeting HER proteins in cancer therapy and the role of the non-target HER3. Br J Cancer. 2007; 97: 453-457.

40. Wang S, Zheng G, Chen L, Xiong B. Effect of HER-2/neu over-expression on prognosis in gastric cancer: a metaanalysis. Asian Pac J Cancer Prev. 2011; 12: 1417-1423.

41. Begnami MD, Fukuda E, Fregnani JH, Nonogaki S, Montagnini AL, da Costa WL Jr, Soares FA. Prognostic implications of altered human epidermal growth factor receptors (HERs) in gastric carcinomas: HER2 and HER3 are predictors of poor outcome. J Clin Oncol. 2011; 29: 3030-3036.
42. Kapitanović S, Radosević S, Slade N, Kapitanović M, Andelinović S, Ferencić Z, Tavassoli M, Spaventi S, Pavelić $\mathrm{K}$, Spaventi R. Expression of erbB-3 protein in colorectal adenocarcinoma: correlation with poor survival. J Cancer Res Clin Oncol. 2000; 126: 205-211.

43. Lédel F, Stenstedt K, Hallström M, Ragnhammar P, Edler D. HER3 expression is correlated to distally located and low-grade colon cancer. Acta Oncol. 2016; 55: 875-880.

44. Ginestier C, Charafe-Jauffret E, Penault-Llorca F, Geneix J, Adélaïde J, Chaffanet M, Mozziconacci MJ, Hassoun J, Viens P, Birnbaum D, Jacquemier J. Comparative multimethodological measurement of ERBB2 status in breast cancer. J Pathol. 2004; 202: 286-298.

45. Gjerdrum LM, Sorensen BS, Kjeldsen E, Sorensen FB, Nexo E, Hamilton-Dutoit S. Real-time quantitative PCR of microdissected paraffin-embedded breast carcinoma: an alternative method for HER-2/neu analysis. J Mol Diagn. 2004; 6: 42-51.

46. Vinatzer U, Dampier B, Streubel B, Pacher M, Seewald MJ, Stratowa C, Kaserer K, Schreiber M. Expression of HER2 and the coamplified genes GRB7 and MLN64 in human breast cancer: quantitative real-time reverse transcriptionPCR as a diagnostic alternative to immunohistochemistry and fluorescence in situ hybridization. Clin Cancer Res. 2005; 11: 8348-8357.

47. Lottner C, Schwarz S, Diermeier S, Hartmann A, Knuechel R, Hofstaedter F, Brockhoff G. Simultaneous detection of HER2/ neu gene amplification and protein overexpression in paraffinembedded breast cancer. J Pathol. 2005; 205: 577-584.

48. Koutras AK, Kalogeras KT, Dimopoulos MA, Wirtz RM, Dafni U, Briasoulis E, Pectasides D, Gogas H, Christodoulou C, Aravantinos G, Zografos G, Timotheadou E, Papakostas P, et al. Evaluation of the prognostic and predictive value of HER family mRNA expression in highrisk early breast cancer: a Hellenic Cooperative Oncology Group (HeCOG) study. Br J Cancer. 2008; 99: 1775-1785.

49. Moher D, Liberati A, Tetzlaff J, Altman DG. Preferred reporting items for systematic reviews and meta-analyses: the PRISMA statement. Int J Surg. 2010; 8: 336-341.

50. Begg CB, Mazumdar M. Operating characteristics of a rank correlation test for publication bias. Biometrics. 1994; 50: 1088-1101.

51. Egger M, Davey SG, Schneider M, Minder C. Bias in metaanalysis detected by a simple, graphical test. BMJ. 1997; 315: 629-634. 